\title{
Radixin inhibition decreases adult neural progenitor cell migration and proliferation in vitro and in vivo
}

\author{
Åsa Persson, Olle R. Lindberg and Hans G. Kuhn*
}

Center for Brain Repair and Rehabilitation, Institute of Neuroscience and Physiology, Sahlgrenska Academy, University of Gothenburg, Gothenburg, Sweden

\author{
Edited by: \\ Lawrence Rajendran, University \\ Zurich, Switzerland \\ Reviewed by: \\ Alexandra Lerch-Gaggl, Medical \\ College of Wisconsin, USA \\ Shaohua Yang, University of North \\ Texas Health Science Center, USA \\ *Correspondence: \\ Hans G. Kuhn, Center for Brain Repair \\ and Rehabilitation, Institute of \\ Neuroscience and Physiology, \\ Sahlgrenska Academy, University of \\ Gothenburg, Box 436, 40530 \\ Gothenburg, Sweden \\ e-mail: georg.kuhn@neuro.gu.se
}

Neuronal progenitors capable of long distance migration are produced throughout life in the subventricular zone (SVZ). Migration from the SVZ is carried out along a well-defined pathway called the rostral migratory stream (RMS). Our recent finding of the specific expression of the cytoskeleton linker protein radixin in neuroblasts suggests a functional role for radixin in RMS migration. The ezrin-radixin-moesin (ERM) family of proteins is capable of regulating migration through interaction with the actin cytoskeleton and transmembrane proteins. The ERM proteins are differentially expressed in the RMS with radixin and moesin localized to neuroblasts, and ezrin expression confined to astrocytes of the glial tubes. Here, we inhibited radixin function using the quinocarmycin analog DX52-1 which resulted in reduced neuroblast migration in vitro, while glial migration remained unaltered. Furthermore, the morphology of neuroblasts was distorted resulting in a rounded shape with no or short polysialylated neural cell adhesion molecule positive processes. Intracerebroventricular infusion of the radixin inhibitor resulted in accumulation of neuroblasts in the anterior SVZ. Neuroblast chains were short and intermittently interrupted in the SVZ and considerably disorganized in the RMS. Moreover, we studied the proliferation activity in the RMS after radixin inhibition, since concentrated radixin expression has been demonstrated in the cleavage furrow of dividing cells, which indicates a role of radixin in cell division. Radixin inhibition decreased neuroblast proliferation, whereas the proliferation of other cells in the RMS was not affected. Our results demonstrate a significant role for radixin in neuroblast proliferation and migration.

Keywords: ezrin/radixin/moesin, subventricular zone, rostral migratory stream, neuronal migration, proliferation

\section{INTRODUCTION}

In the adult rodent brain neuronal progenitor cells, neuroblasts, migrate a long distance from the neurogenic subventricular zone (SVZ) through the rostral migratory stream (RMS) to their final destination in the olfactory bulb $(\mathrm{OB})$ where they differentiate into mature neurons (Altman, 1969; Lois and Alvarez-Buylla, 1994). The significance and extent of adult neurogenesis in the adult human SVZ/RMS area is not clear, however, in rodents brain injury and pathology can induce both proliferation and deviated migration from the SVZ/RMS toward damaged tissue areas (Arvidsson et al., 2002; Li et al., 2010; Osman et al., 2011). Abolishing migrating neuroblasts after stroke leads to worsened recovery (Jin et al., 2010), suggesting a supportive role for these neuronal progenitors under injury conditions. A deeper understanding of RMS migration may reveal ways to direct immature cells to damaged areas and to increase possibilities for brain repair. In the RMS, neuroblasts migrate along each other forming cellular chains which are tightly surrounded by glial cells, often referred to as the glial tubes (Lois et al., 1996; Peretto et al., 1997). Chain migration has been proposed to be supported by the glial tubes and blood vessels and, is regulated by numerous extracellular and intracellular cues. Polysialylated neural cell adhesion molecule (PSA-NCAM) is important for the organization of chain migration in the RMS and adjusts cell-cell adhesion (Ono et al., 1994;
Chazal et al., 2000). Doublecortin (DCX) is required for nuclear translocation during neuroblast migration (Gleeson et al., 1999; Koizumi et al., 2006). Moreover, neuroblasts divide en route to the OB and EGF receptors (Anton et al., 2004; Kim et al., 2009); ephrins (Conover et al., 2000; Ghashghaei et al., 2006) and NogoA (Rolando et al., 2012) have been found to regulate both migration and proliferation in the RMS. Cellular functions such as migration and adhesion require a highly dynamic cytoskeleton. Linker proteins of the ERM (ezrin/radixin/moesin) family can interact with both f-actin and several transmembrane proteins, providing a connection between extracellular cues and the cytoskeleton (Sato et al., 1992). The action of ERM proteins is regulated by binding of their two main domains; the N-terminal FERM domain and the C-terminal domain, which can be interrupted by threonine phosphorylation (for review, see Bretscher et al., 2002). An open conformation enables simultaneous binding of ERM proteins to the cytoskeleton and to transmembrane proteins such as receptors, ECM molecules and adhesion proteins (Serrador et al., 1997; Ivetic et al., 2002; Bono et al., 2005; Loebrich et al., 2006; Takai et al., 2007; Tang et al., 2007; Terawaki et al., 2008). Formation of actin-rich structures like filopodia and lamellipodia are essential for cell migration and process formation in various cell types. The involvement of ERM proteins in a variety of cell functions in the embryonic and early postnatal brain, including axonal outgrowth, 
morphological rearrangement, cell migration and signaling, have been demonstrated (Paglini et al., 1998; Castelo and Jay, 1999; Loebrich et al., 2006; Haas et al., 2007; Parisiadou et al., 2009). In the adult brain, however, ERM proteins have been less studied. Although highly homologous, the ERM proteins seem to localize to different cell types in the adult brain, with ezrin expression in glial cells and radixin expression in neuronal cells (Paglini et al., 1998; Gronholm et al., 2005; Cleary et al., 2006; Persson et al., 2010). We recently described the specific expression of radixin in PSA-NCAM ${ }^{+}$neuroblasts in the adult SVZ and RMS (Persson et al., 2010). Here we investigate the function of radixin in neuroblasts using the radixin inhibitor DX52-1, aquinocarmycin analog. The inhibitor was recently shown to primarily target radixin and disrupt the ability for radixin to bind actin as well as transmembrane proteins, such as CD44 (Kahsai et al., 2006). In this study, we explore the effects of DX52-1 and radixin inhibition on neuroblasts in the adult SVZ and RMS using in vitro and in vivo approaches to analyze migration, proliferation, cell death, and proteomic changes.

\section{MATERIALS AND METHODS CHEMICALS}

The quinocarmycin analog DX52-1 (generous gift from Prof. Gabriel Fenteany) was used to block radixin function as described previously (Kahsai et al., 2006). A stock solution was prepared by dissolving the compound in sterile 50\% DMSO in PBS which was further diluted with PBS to the final concentration $(<0.05 \%$ for in vivo experiments and $<0.0025 \%$ DMSO for in vitro experiments). Control experiments were always performed with the same concentration of DMSO as the corresponding diluted DX52-1 solution.

\section{ANIMALS}

Eight to nine week-old male Wistar rats were used in this study. All rats were housed in a barrier facility with a 12-h light/dark cycle and allowed free access to food and water. Experiments were conducted according to protocols approved by the Gothenburg ethics committee of the Swedish Animal Welfare Agency (Ethical application no 32/11 and 145/10). For in vitro studies and whole mount preparations, animals were anesthetized using isofluorane and brains removed after decapitation.

\section{SURGERY}

Surgeries were performed under ketamine $(33 \mathrm{mg} / \mathrm{mL}$ Ketalar, Pfizer, New York, NY, USA) and xylazine (6.67 mg/mL Rompun, Bayer Healthcare AG, Tarrytown, NY, USA) anesthesia, and all efforts were made to minimize suffering. The animals were divided into two groups receiving either vehicle (0.05\% DMSO in PBS) or DX52-1 (1.3 $\mu \mathrm{g} / \mathrm{day})$, for 4 days. The surgeries were performed as previously described (Lindberg et al., 2012). Briefly, osmotic minipumps (Model 1002; Alzet-Durect, Cupertino, CA, USA) and infusion cannulas (Brain Infusion Kit 2; Alzet-Durect) were filled with vehicle or DX52-1. Cannulas were inserted intracerebroventricularly using a stereotaxic instrument [David Kopf, Tujunga, CA and Stoelting Co, Wood Dale, IL, USA; anteroposterior (AP) $+8.5 \mathrm{~mm}$, lateral $+1.2 \mathrm{~mm}$ from the center of the interaural line at flat skull position; cannula length, $5 \mathrm{~mm}$ below skull] and the minipumps were placed subcutaneously. At the end of the DX52-1 infusion period, animals were sedated using an overdose of pentobarbital and transcardially perfused with 4\% PFA (Histolab, Gothenburg, Sweden) in 0.1 M phosphate buffer ( $\mathrm{pH} 7.4$ ). Brains were removed, postfixed for $24 \mathrm{~h}$ in $4 \%$ PFA (Thermo Fisher Scientific, Waltham, MA, USA) and thereafter kept in 30\% sucrose at $4^{\circ} \mathrm{C}$ until further processed.

\section{IMMUNOFLUORESCENCE}

The ipsilateral side of infused brains was cut in a sagittal plane and the contralateral side was cut coronally. Sagittal sections were cut at $25 \mu \mathrm{m}$ and coronal sections were cut at $40 \mu \mathrm{m}$ on a sliding microtome (Leica Microsystems, Wetzlar, Germany) followed by immunofluorescence. Immunostainings including radixin were preceded by antigen retrieval in sodium citrate, $\mathrm{pH}$ 6.0 , for $20 \mathrm{~min}$ at $97^{\circ} \mathrm{C}$ followed by $15 \mathrm{~min}$ cooling at room temperature. Sections were blocked for $30 \mathrm{~min}$ in $3 \%$ normal donkey serum (Jackson ImmunoResearch, West Grove, PA, USA) in $0.1 \%$ Triton $\mathrm{X}-100$, and then incubated for $48 \mathrm{~h}$ at $4^{\circ} \mathrm{C}$ in primary antibodies; monoclonal rabbit anti-radixin (Abcam, Cambridge, MA, USA), mouse anti-radixin (Abnova, Taipei City, Taiwan), rabbit anti-phosphorylated ezrin/radixin/moesin (Cell signaling, Danvers, MA, USA), rabbit anti-phosphorylated histone $\mathrm{H} 3$ (PHH3, Millipore, Billerica, MA, USA), mouse IgM anti-PSA-NCAM (Chemicon International/Millipore, Billerica, MA, USA). ToPro-3 (Molecular Probes/Invitrogen, Carlsbad, CA, USA) was used as a nuclear counterstain. After rinsing in trisbuffered saline (TBS), sections were incubated for $2 \mathrm{~h}$ with Alexa Fluor-conjugated secondary antibodies (Molecular Probes) and CF secondary antibodies (Biotium, Hayward, CA, USA). The sections were mounted on glass slides and coverslipped with ProLong Gold DAPI (Molecular Probes).

To study apoptotic cell death in the SVZ and RMS after DX52-1 infusion, the ApopTag Fluorescein Direct in situ Apoptosis Detection kit (Millipore) was used. Fixed free floating sections were mounted onto glass slides and pretreated with ethanol:acetic acid (2:1) for $5 \mathrm{~min}$ at $-20^{\circ} \mathrm{C}$ followed by a PBS washing step. After $1 \mathrm{~h}$ of incubation in terminal deoxynucleotidyltransferase at $37^{\circ} \mathrm{C}$, the reaction was stopped by washing and the sections were incubated for $30 \mathrm{~min}$ with a Fluorescein-conjugated anti-digoxigenin antibody at room temperature and subsequently washed in PBS. The slides were coverslipped with ProLong Gold DAPI (Molecular Probes).

\section{SVZ WHOLE MOUNT PREPARATION}

After 4 days of vehicle or DX52-1 intracerebroventricular infusion, brains $(n=3)$ were removed and placed in $37^{\circ} \mathrm{C}$ warm Hank's Balansed Salt Solution (HBSS, Invitrogen). The whole ventricular wall of the contralateral hemisphere, including the underlying parenchyma, was carefully dissected out and fixed in cold $4 \%$ PFA/0.1\% Triton X-100 in PBS for $24 \mathrm{~h}$ before washing and blocking unspecific binding in 10\% Donkey serum/2\% Triton X-100 in PBS for $1 \mathrm{~h}$ (Mirzadeh et al., 2010). The wholemount was incubated for $48 \mathrm{~h}$ with primary antibodies; goat anti-DCX (Santa Cruz Biotechnology, Inc., Santa Cruz, CA, USA), rabbit anti-PhosH3 (Millipore), washed thoroughly in $0.1 \%$ Triton X-100 in PBS, and subsequently incubated for $24 \mathrm{~h}$ in Alexa Fluor secondary 
antibodies (Molecular Probes). After completing the staining, a sliver of the SVZ was cut out from the underlying parenchyma and coverslipped with Prolong Gold DAPI (Molecular Probes).

\section{SVZ EXPLANTS}

For explant cultures brains were rapidly removed and kept in Hank's balanced salt solution (Gibco/Invitrogen) on ice. One millimeter coronal brain slices were cut between anterio-posterior coordinates Bregma -0.5 to 2.5 using a coronal brain matrix. The slices were kept on ice while the lateral ventricle walls were dissected and cut into approximately $100 \mu \mathrm{m}$ diameter pieces. The tissue pieces were resuspended in Neurobasal A medium (Invitrogen), mixed 3:1 with Matrigel (BD Biosciences, San Jose, CA, USA) and dispensed in 8-well chamber slides (BD Bioscience), followed by $10 \mathrm{~min}$ polymerization at $37^{\circ} \mathrm{C}$. Explants were cultured in Neurobasal A medium, supplemented with B27 and Glutamax, PenStrep (all Invitrogen) and a concentration series of the radixin inhibitor DX52-1 (Vehicle 0.0025\% DMSO, 50, 100 or $250 \mathrm{nM}$ ) at $37^{\circ} \mathrm{C}$ in $5 \% \mathrm{O}_{2}$ and $1 \% \mathrm{CO}_{2}$ for $72 \mathrm{~h}$. At the end of the experiment the explants were fixed in 4\% PFA for $20 \mathrm{~min}$. After three 15-min washes in TBS, the explants were blocked for $3 \mathrm{~h}$ at room temperature using $3 \%$ donkey serum and $0.2 \%$ Triton-X in TBS. Explants were then incubated with primary antibodies for $48 \mathrm{~h}$; goat anti-Sox2 (Santa Cruz Biotechnology), rabbit anti-GFAP (DakoCytomation, Glostrup, Denmark), mouse IgM anti-PSANCAM (Chemicon International) and with secondary antibodies as described above.

Apoptosis and cell death was analyzed using Vybrants Apoptosis Assay kit 2 (Molecular Probes) on explants after $96 \mathrm{~h}$ in culture. Explants were washed in cold PBS for $10 \mathrm{~min}$ and subsequently in Annexin buffer for $15 \mathrm{~min}$ followed by incubation with Annexin $\mathrm{V}$ conjugated with Alexa 488 and propidium iodide (PI) in room temperature for $40 \mathrm{~min}$. The cultures were washed in Annexin buffer, fixed with 2\% PFA and stained with the nuclear stain ToPro-3 (Molecular Probes) before one wash in Annexin buffer and subsequently coverslipped with ProLong Gold (Molecular Probes).

\section{CONFOCAL MICROSCOPY AND OUANTIFICATIONS}

Immunofluorescence labeling was imaged using confocal laser scanning microscope (Leica TCS SP2, Leica Microsystems, Wetzlar, Germany, and at the Centre for Cellular Imaging; Zeiss LSM 700 and Zeiss LSM 710, Carl Zeiss Microscopy GmbH, Jena, Germany). For SVZ explant cultures, migration distance of migratory chains was measured for PSA-NCAM ${ }^{+}$cells. The three longest migratory chains per explant were used to estimate the maximum migration distance under DX52-1 treatment (1-4 explants). Furthermore, the percentage of PSA-NCAM ${ }^{+}$and Sox $2^{\text {high }}$ cells leaving the explants were quantified by counting the ratio of PSA-NCAM ${ }^{+}$ and Sox $2^{\text {high }}$ cells (total cells counted per condition: $549 \pm 66$ ) in migratory chains emerging from the explants. Cells were visualized with the nuclear stain ToPro-3 and $n=4$ for all explant quantifications.

For in vivo quantifications coronal sections from the contralateral hemisphere were used after vehicle or DX52-1 infusion. For quantification of cell proliferation in the RMS, the total number of $\mathrm{PHH}^{+}$cells, and PSA-NCAM ${ }^{+} / \mathrm{PHH}^{+}$double labeled cells, in the RMS was acquired from 7 to 9 sections at a 1:12 interval covering the RMS. Anterior RMS refers to anterio-posterior coordinates from 13.20 to $11.52 \mathrm{~mm}$ from interaural line and posterior RMS refers to anterio-posterior coordinates from 11.52 to $10.44 \mathrm{~mm}$ from interaural line. Double labeling was assumed when cells exhibited direct co-localization or when nucleus and cytosol or processes from the same cell were individually labeled. Area/volume measurements and the number of ApopTag stained cells were assessed using stereology software (Stereo Investigator; MicroBrightField Inc., Williston, VT, USA).

\section{PROTEOMIC ANALYSIS}

The proteomic analysis was performed by the Proteomics core facility at the University of Gothenburg. Relative protein expression levels was analyzed after radixin inhibition using the TMT isotopic mass tagging kit (Thermo Fisher Scientific), where the reporter mass is used for semi quantitative identification of proteins with tandem mass spectrometry. The ipsilateral SVZ was microdissected from rats $(n=3)$ after intracerebroventricular infusion of DX52-1 or vehicle. Tissue samples were lysed in a buffer containing; $50 \mathrm{mM}$ TEAB, $8 \mathrm{M}$ Urea, 4\% Chaps, $0.2 \%$ SDS, $5 \mathrm{mM}$ EDTA, pH 8.5. Total protein concentration was determined using Pierce $660 \mathrm{~nm}$ Protein Assay (Thermo Fisher Scientific). $100 \mu \mathrm{g}$ protein per sample were incubated with TCEP (tris(2-carboxyethyl)phosphine), alkylated with MMTS (methyl methanethiosulfonate) and digested with trypsin, after a four-fold dilution, in $0.5 \mathrm{M}$ TEAB ratio $1: 25$ over night in $37^{\circ} \mathrm{C}$.

TMT 6-plex reagents (126-131) were dissolved in ACN and added to the respectively sample according to manufacturer's protocol (Thermo Fisher Scientific). After labeling and quenching of the reagents, the samples were combined and concentrated. TMT-labeled peptides were separated with strong cation exchange chromatography (SCX). The 18 peptide containing fractions were desalted on PepClean C18 spin columns according to manufacturer's instructions (Thermo Fisher Scientific). The desalted and dried fractions were reconstituted into $0.1 \%$ formic acid and analyzed on a LTQ-Orbitrap-Velos (Thermo Fisher Scientific) interfaced with an in-house constructed nano-LC column. Two-micro liter sample injections were made with an Easy-nLCautosampler (Thermo Fisher Scientific), running at $200 \mathrm{~nL} / \mathrm{min}$. The peptides were trapped on a precolumn $(45 \times 0.075 \mathrm{~mm}$ i.d. $)$ and separated on a reversed phase column, $200 \times 0.075 \mathrm{~mm}$, packed in-house with $3 \mu \mathrm{m}$ Reprosil-Pur C18-AQ particles. The gradient was as followed; 0-60 min 5-25\% acetonitrile (ACN), 0.1\% formic acid, $60-75 \mathrm{~min} 25-80 \% \mathrm{ACN}, 0.1 \%$ formic acid and the last $15 \mathrm{~min}$ at $90 \% \mathrm{ACN}, 0.1 \%$ formic acid. LTQ-OrbitrapVelos settings were: spray voltage $1.4 \mathrm{kV}, 1$ microscan for MS1 scans at 60,000 resolutions $(\mathrm{m} / \mathrm{z} 400)$, full mass spectrometry (MS) mass range $\mathrm{m} / \mathrm{z}$ 400-1,800. The LTQ-OrbitrapVelos was operated in a data-dependent mode with one MS1 FTMS scan precursor ions followed by HCD (high energy collision dissociation), MS2 scans of the 10 most abundant protonated ions in each FTMS scan. Dynamic exclusion of a precursor during $30 \mathrm{~s}$ was used after one repeat for MS2. All fractions were analyzed a second time using an exclusion list of $\mathrm{m} / \mathrm{z}$ for all identified peptides.

Mass spectrometry raw data files from all SCX fractions for the TMT set were merged for relative quantification and identification 
using Proteome Discoverer version 1.3 (Thermo Fisher Scientific). Database search was performed by Mascot search engine using the following critera: Swissprot rat protein database, MS peptide tolerance as $10 \mathrm{ppm}$, MS/MS tolerance as $0.1 \mathrm{Da}$, trypsin digestion allowing one missed cleavages with variable modifications; methionine oxidation, cysteine methylthiol, and fixed modifications; N-terminal TMT-label, lysine TMT-label. The detected protein threshold in the software was set to $99 \%$ confidence and identified proteins were grouped by sharing the same sequences to minimize redundancy.

For TMT quantification, the ratios of TMT reporter ion intensities in MS/MS spectra (m/z 126.12, 127.13, 128.13, 129.14, 130.14, 131.14) from raw data sets were used to calculate fold changes between samples. The average of all three reporters for the control group were used as the denominator. Only peptides unique for a given protein were considered for relative quantitation, excluding those common to other isoforms or proteins of the same family. The resulting ratios were then exported into Excel for data interpretation. The total group of 32 significantly changed proteins were analyzed using the software Ingenuity Pathway Analysis (IPA; Ingenuity systems, Redwood City, CA, USA).

\section{STATISTICS}

Statistical differences of in vivo quantifications were analyzed using the 2-tailed Student's $t$-test. For in vitro experiments, one-way ANOVA and Bonferroni post hoc test were employed. All error bars represent standard error of the mean (s.e.m.). All statistical calculations and graphical visualizations, except for the proteomics analysis, were performed in GraphPad Prism 5 (GraphPad Software, La Jolla, CA, USA). For the proteomic analysis Welsh $t$-test was used. Differences of $p<0.05$ were considered statistically significant $\left({ }^{*}\right)$.

\section{RESULTS}

\section{SPECIFIC TARGETING OF PSA-NCAM+ PROGENITOR CELL MIGRATION} BY RADIXIN INHIBITION IN VITRO

To determine the influence of radixin inhibition on progenitor cell migration, we incubated SVZ explants with increasing concentrations of the radixin inhibitor DX52-1 for $72 \mathrm{~h}$ to determine the migration distance (Figures 1A-C). For PSA-NCAM positive neuronal progenitor cells $\left(\mathrm{PSA}_{\mathrm{NCAM}}{ }^{+}\right.$), the average distance migrated was significantly reduced by inhibitor concentrations of $50 \mathrm{nM}$ and higher (Figure 1D). Moreover, a reduced portion of $\mathrm{PSA} \mathrm{NCAM}^{+}$cells migrated out from the explants under radixin inhibition at 100 and $250 \mathrm{nM}$ DX52-1 (Figure 1F). The neuroblast chains had an altered morphology with a short leading process expressing PSA-NCAM and occasionally neuroblasts had a completely circular cell membrane and were situated close to the explant. Since a reduced migratory response could be due to toxicity of the radixin inhibitor, we assayed apoptosis and cell death using Annexin V and PI staining of cells emerging from the explants. There was no difference in the ratio of Annexin V (Figure 2A) or PI (Figure 2B) labeled cells under control conditions compared to 50, 100 or 250 nMof the inhibitor.

To test ifDX52-1 treatment exclusively affects migration of neuroblasts, we analyzed the migration pattern of cells expressing high

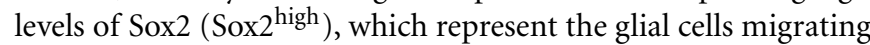

from SVZ explants under control conditions. Sox2 expression is present in migrating neuroblasts, but at lower levels (Figure 3B) (Ferri et al., 2004). A common marker for glial cells is the glial fibrillary acidic protein (GFAP). The majority of cells migrating in SVZ explant cultures under control conditions express Sox 2 high and a smaller fraction express GFAP (Figure 3A). Almost all $\mathrm{GFAP}^{+}$cells were also Sox $2^{\text {high }}$ (Figure 3A). No statistical difference in the migration distance of glial Sox $2^{\text {high }}$ cells could be discerned at any concentration of the inhibitor (Figure 1E). Sox $2^{\text {high }}$ cells migrated also under treatment with the highest concentration $(250 \mathrm{nM})$ of the inhibitor. As a consequence, at the highest concentrations of DX52-1, the reduced migration of PSA$\mathrm{NCAM}^{+}$cells, led to an increased percentage of migratory Sox 2 high cells surrounding the explants (Figure 1F).

\section{RADIXIN INHIBITION IN VIVO RESULTS IN DISORGANIZED NEUROBLAST CHAIN FORMATION AND ACCUMULATION IN THE POSTERIOR RMS}

Effects of radixin inhibitonin the SVZ and RMS were analyzed by intracerebroventricular infusion of DX52-1. Wholemount preparations of the lateral ventricle wall was used to analyze the overall organization of neuroblast chains in the SVZ. In the dorsal SVZ of naive animals, large amounts of DCX positive neuroblast chains were organized parallel to the corpus callosum and directed towards the anterior SVZ. In addition, long cell chains spanned the entire SVZ (Figures 4A,B). In coronal sections of the control RMS the neuroblasts chains were organized in tight cell bundles (Figure 4C). In contrast, under radixin inhibition neuroblast chain formation in the SVZ were randomly oriented and displayed short intermittently interrupted cell chains (Figure 4D). The morphology of $\mathrm{DCX}^{+}$cells wasless polarized and the neuroblastsformed clusters (Figure 4E). In the RMS, radixin inhibition resulted in similarly disorganized chains (Figure 4F). Previous studies show that the interaction between radixin and f-actin require phosphorylation of a threonine residue on the C-terminal end of radixin (Tsukita et al., 1997). After treatment with DX52-1, images indicate a reduced immunoreactivity for phosphorylated radixin in the RMS (Figures 5A-D).

The phenotype of neuroblasts described above is likely the cause of accumulation of neuroblasts in the anterior SVZ as evident by PSA-NCAM immunoreactive cells in coronal sections after DX52-1 infusions, in the posterior RMS (Figures 6A-D). In the posterior RMS the volume of the was increased (Figure 6I) whereas no difference was found in the volume of the anterior RMS (Figure 6F).

\section{RADIXIN INHIBITION AFFECTS PROLIFERATION OF NEUROBLASTS IN THE RMS}

High amounts of radixin have been demonstrated in the cleavage furrow of dividing cells (Sato et al., 1991), suggesting an involvement of this protein in cell proliferation. A large proportion of neuroblasts divide en route from the SVZ to the OB (Luskin, 1993). Quantifying the number of cells expressing both the cell cycle marker PHH3 and PSA-NCAM (Figures $6 \mathbf{E}, \mathbf{E}^{\prime}, \mathbf{E}^{\prime \prime}$ ) revealed that fewer neuroblasts divided after radixin inhibition in both the anterior and posterior RMS (Figures 6G,J). However, there was no difference in proliferation in the glial population (PSA-NCAM 

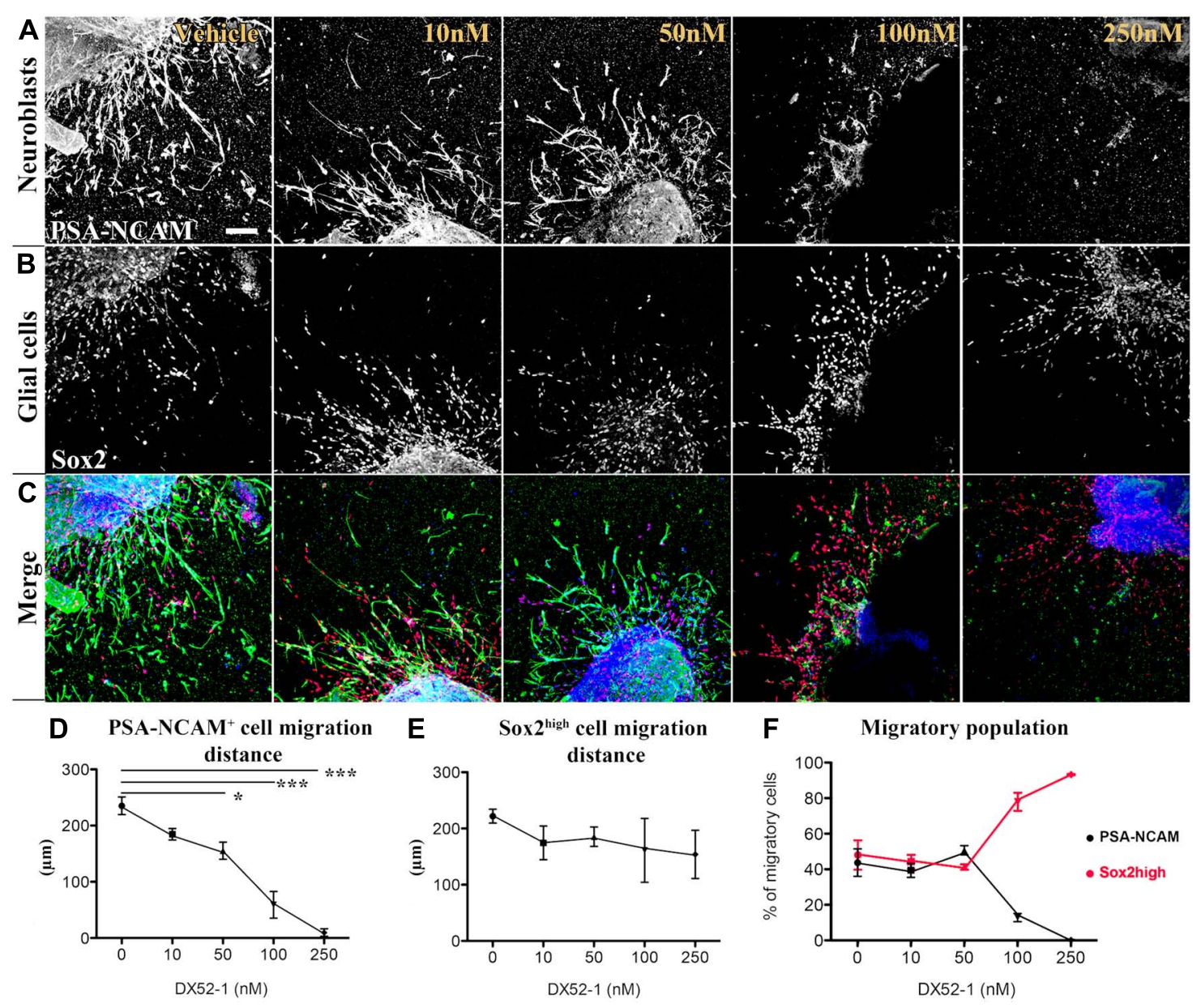

FIGURE 1 | Dose-dependent decrease in migration distance of neuronal progenitor cells from SVZ explants under radixin

inhibition. Neural and glial progenitor cells are visualized by PSA-NCAM and Sox2 immunofluorescence. (A) Color separation for PSA-NCAM

(top row) and (B) Sox-2 (middle row) expressing cells under increasing concentrations of the radixin inhibitor DX52-1 (Vehicle, 10, 50, 100, and 250 nM). (C) Bottom row depicts color merge of PSA-NCAM (green),
Sox-2 (red) immunoreactivity with Topro-3 as a nuclear stain (blue). (D) Migration distance $(\mu \mathrm{m})$ of PSA-NCAM+ cells under DX52-1 treatment. (E) Migration distance $(\mu \mathrm{m})$ of Sox $2^{\text {high }}$ glial cells under DX52-1 treatment. (F) The fraction of cells expressing PSA-NCAM+ (black line) and Sox $2^{\text {high }}$ (red line) in the population that migrated from the explants $\left({ }^{*} p<0.05,{ }^{* *} p<0.01,{ }^{* *} p<0.001\right)$. Scale bar $=100 \mu \mathrm{m}$.
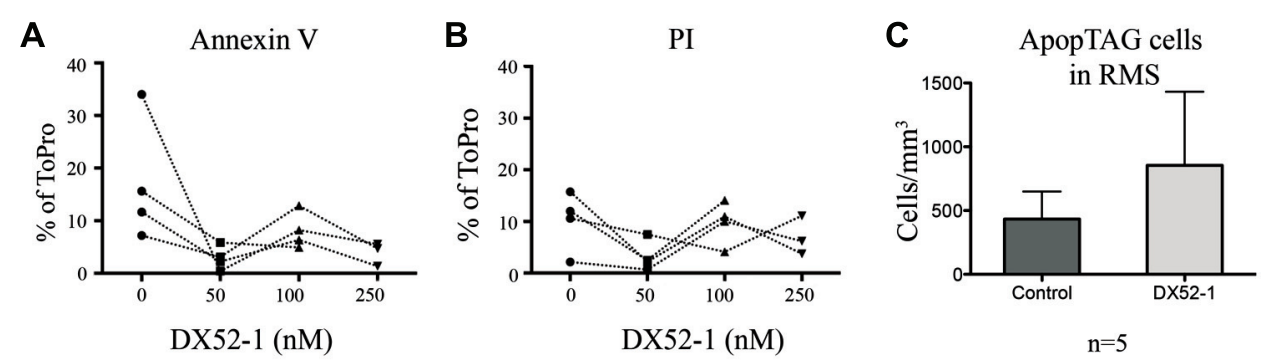

FIGURE 2 | No increase in cell death of progenitor cells in vitro or in vivo under radixin inhibition. Paired results from four different experiments showed no significant difference in thepercentage of cells that migrated out from SVZ explant cultures being AnnexinV postitive (A) or PI positive (B) under different concentrations of the radixin inhibitor DX52-1 (Vehicle, 50, 100 , and $250 \mathrm{nM}$ ). (C) The number of TUNEL positive cells was quantified per volume in the RMS after 4 days of intracerebroventricular infusion of vehicle or DX52-1 $(n=5)$. 


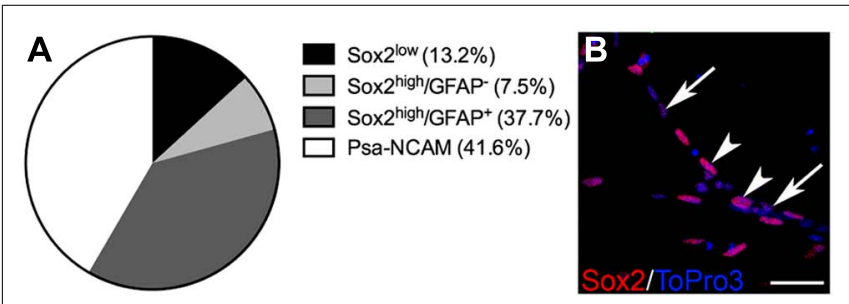

FIGURE 3 | Cell populations migrating in SVZ explant cultures. (A) Percentage of cells positive for the markers PSA-NCAM, Sox2 and GFAP, in the SVZ explant experiment. All analyzed cells migrating out from the explants expressed Sox2, in low or high levels. Similar proportions of neuronal (PSA-NCAM ${ }^{+}$) and glial $\left(\mathrm{GFAP}^{+}\right)$cells migrated in the SVZ explants cultures and the majority of the GFAP ${ }^{+}$cells expressed Sox $2^{\text {high }}$ (B) Examples of Sox $2^{\text {low }}$ (arrows) and Sox $2^{\text {high }}$ (arrowheads) cells. Scale bar in $\mathbf{( B )}=20 \mu \mathrm{m}$

negative cells) in the RMS (Figures $\mathbf{6 H}, \mathbf{K}$ ). To assess induction of apoptosis due to the DX52-1 treatment in vivo we analyzed the number of TUNEL positive cells in the RMS; however, no significant difference was detected (Figure 2C).

\section{ALTERED PROTEIN EXPRESSION AFTER RADIXIN INHIBITION}

To study protein expression changes after treatment with DX52-1, the ipsilateral SVZ was dissected after 4 days of intracerebroventricular infusion of DX52-1 or vehicle (each $n=3$ ). Using isobaric labeling and LC-MS/MS, 32 proteins were identified with significantly changed expression levels after treatment (Table 1). Functional analysis of all significantly changed proteins was performed using IPA (Ingenuity Systems, Redwood City, CA,
USA) identifying two associated functional networks: (1) cell morphology, cellular development, small molecule biochemistry (enrichment score $=48$ ); (2) cell-to-cell signaling and interaction, cellular development, developmental disorder (enrichment score $=30$ ). The protein list was enriched for proteins involved in a number of basic molecular and cellular functions including cellular assembly and organization, which correlates well with the predicted functions of radixin (Figure 7).

A number of proteins involved in cell-to-cell signaling and interaction changed expression levels, such as the metabotropic glutamate receptor 5 (mGluR5), arrestin $\beta 1$ and adenylatecyclase 5. The cytoskeleton components dynactin and alpha tubulin were enriched after DX52-1 treatment. Furthermore, proteins involved in molecular and vesicular transport, such as mitochondrial import inner membrane translocase, Scl6a17, syntaxin-12, synapsin-2, peroxisomal membrane protein PEX14 and flotillin-1 were altered. The suppressor of G2 allele SKP1 homolog, a protein regulating the transition from G2 to M-phase, was reduced, corroborating the in vivo results of decreased proliferation after radixin inhibition.

Altered proteins involved in protein metabolism include cytoplasmic tryptophanyl-tRNAsynthetase, V-type proton ATPase, cytoplasmic aspartate aminotransferase, mitochondrial ATP synthase-coupling factor 6, and heterogeneous nuclear riboprotein D0.

\section{DISCUSSION}

The data presented in the current study suggest a role for radixin in neuronal progenitor migration and proliferation. We have
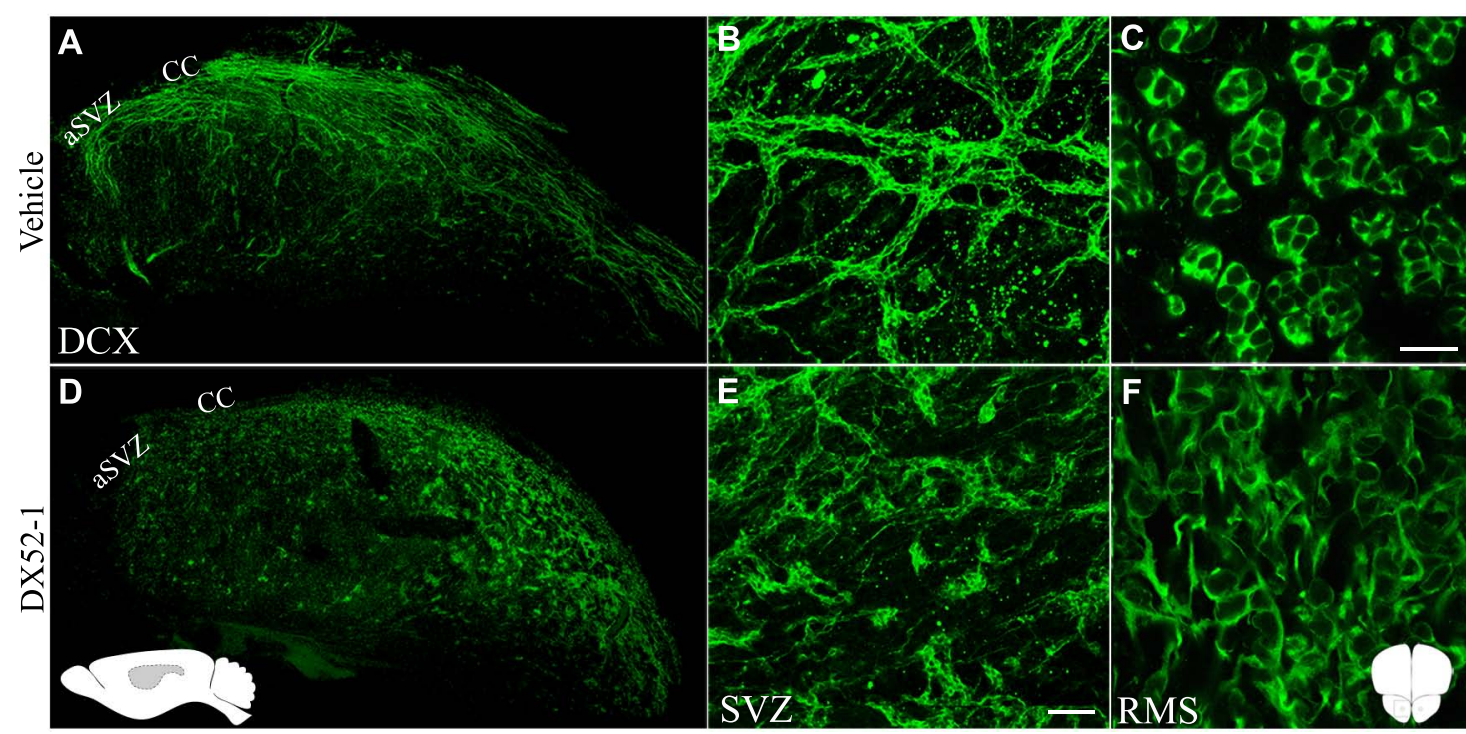

FIGURE 4 | Aberrant morphology of neuroblastsin the SVZ and RMS after radixin inhibition. Overview $(\mathbf{A})$ and magnification $(\mathbf{B})$ of whole mount preparations of the lateral ventricular wall stained for DCX in control animals showing long and well organized neuroblast chains. (C) The RMS in a coronal section showing the tight association of $\mathrm{DCX}^{+}$neuroblast within cellular chains in control animals. Overview (D) and magnification (E) of whole mount preparations of the lateral ventricular wall stained for
DCX after DX52-1 infusion showing short and abnormalneuroblasts in aggregations. (F) The RMS in a coronal section showing the disorganized arrangement of $\mathrm{DCX}^{+}$neuroblasts after DX52-1 infusion. Schematic inset in (D) represent the sagittal brain orientation, and in gray the area, of images (A) and (D). Schematic inset in (F) represent the coronal orientation of images (C) and (F). Scale bar in (C) $=50 \mu \mathrm{m}$, and (E) $=200 \mu \mathrm{m}$. 


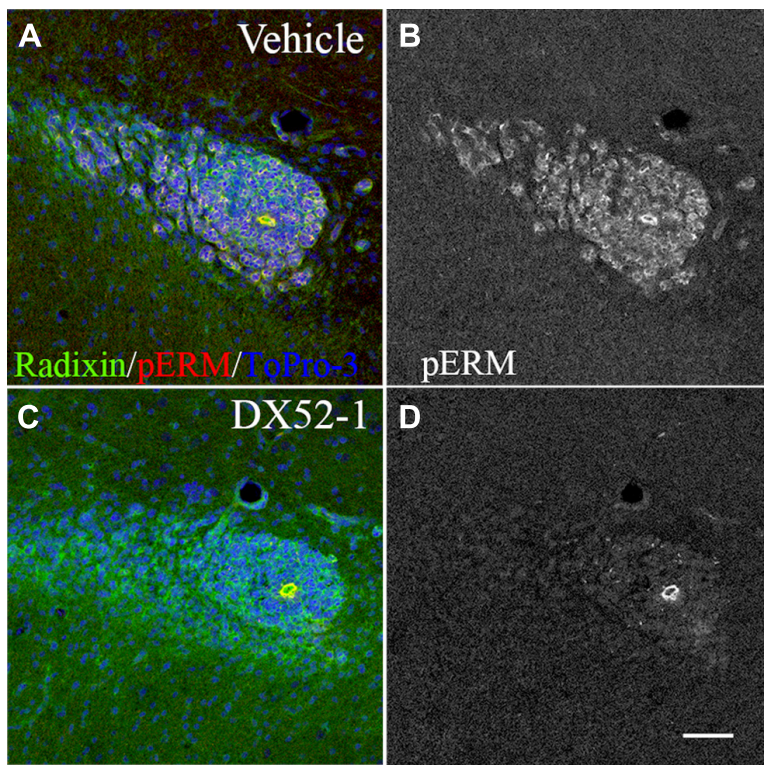

FIGURE 5 | Decreased phosphorylation of radixin in the RMS after DX52-1 treatment. (A) Merged image of radixin and phosphorylated rzrin/radixin/moesin (pERM) immunoreactivity in a coronal section of the control RMS. (B) pERM immunoreactivity in the control RMS. (C) Merged image of radixin and phosphorylated ezrin/radixin/moesin (pERM) immunoreactivity in a coronal section in the DX52-1 treated RMS (D) pERMimmunoreactivity in the DX52-1 treated RMS. Radixin/pERM immunopositive circular structures in $B$ and $D$ are likely residual ependymal cells originating from the wall of the collapsed olfactory ventricle (Peretto etal., 1997). Ependymal cells are known to express high levels of ezrin which explains sustained pERM expression in this area in both control and DX52-1 treated RMS. Scale bar $=50 \mu \mathrm{m}$. previously shown that radixin is specifically expressed in migrating neuroblasts in the RMS of the adult rodent brain (Persson et al., 2010). The current study confirms the expression of radixin in $\mathrm{PSA}-\mathrm{NCAM}^{+}$migratory cells, both in vivo and in vitro. Blocking radixin with the quinocarmycin analog DX52-1 in vitro resulted in a dose-dependent downregulation of neuroblast migration from SVZ explants. Under control conditions similar numbers of PSA$\mathrm{NCAM}^{+}$neuroblasts and Sox $2^{\text {high }}$ expressing glial cells migrate from the explants. The motility of glial cells was not affected by the inhibitor, supporting previous results describing the expression of ezrin, but not radixin, in glial cells (Cleary et al., 2006; Persson et al., 2010).

DX52-1 specifically binds radixin at low concentration and inhibits its binding to f-actin and the transmembrane protein CD44 (Kahsai et al., 2006). At concentrations above those used in our study, DX52-1 are reported to interact with additional proteins, such as the other ERM proteins, ezrin and moesin, and galectin-3 (Kahsai et al., 2006). Treatment with a low dose of DX52-1 in Madin-Darby canine kidney (MDCK) epithelial cell cultures revealed a decreased ability for wound closure after radixin inhibition (Kahsai et al., 2006), suggesting a role for radixin in migration and/or proliferation of epithelial cells. The selective inhibition of neuroblasts in our study confirms the specificity of DX52-1 for radixin, since Sox $2^{\text {high }}$ glial cells remained migratory in the migration assay. In addition, continued migration of glial cells indicates that the inhibitor is not generally toxic to cells. Furthermore, we can exclude DX52-1 toxicity in the neurogenic niche since the rate of apoptosis or cell death was not increased, neither in vitro nor in vivo.

Intracerebroventricular infusion of DX52-1 resulted in distortion of neuroblast chain formation in the SVZ and the
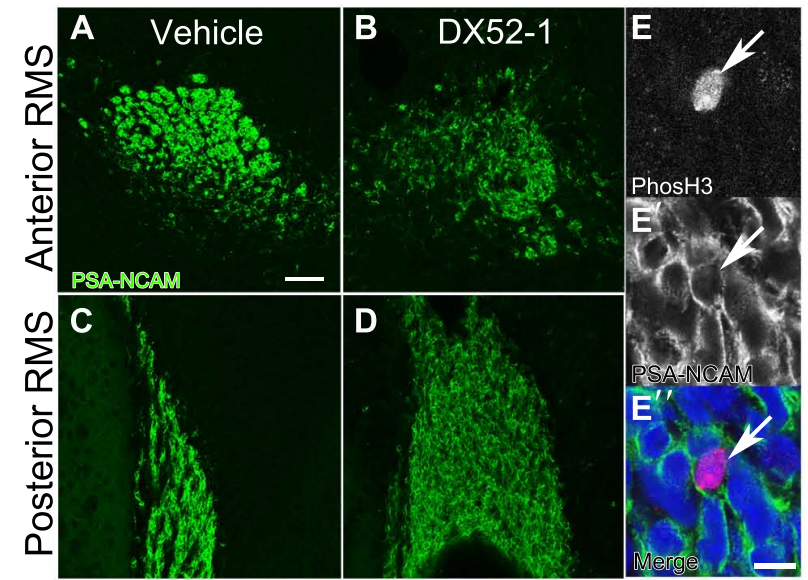

FIGURE 6 | Decreased neuroblast proliferation and accumulation of neuroblastsin the posterior RMS after radixin inhibition. (A, B) PSA-NCAM immunoreactivity in the anterior RMS after 4 days of DX52-1 intracerebroventricular infusion of vehicle (A) or DX52-1 (B). (C, D) PSA-NCAM immunoreactivity in the posterior RMS after 4 days of DX52-1 intracerebroventricular infusion of vehicle (C) or DX52-1 (D) shows an accumulation of PSA-NCAM+ neuroblasts in the posterior RMS after radixin inhibition. (E, $\left.\mathbf{E}^{\prime}, \mathbf{E}^{\prime \prime}\right)$ Example of $\mathrm{PHH}$ (E) immunoreactive cell expressing PSA-NCAM (E') and corresponding merged image in $\left(\mathbf{E}^{\prime \prime}\right)$.
F

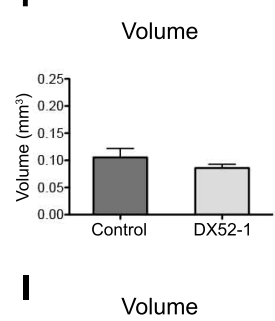

G

$\mathrm{PHH} 3+$ neuroblasts

\section{H}
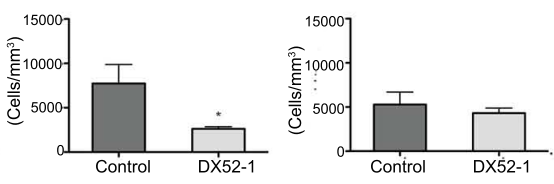

$\mathbf{J}$

$\mathrm{PHH} 3+$ neuroblasts

K $\mathrm{PHH} 3+$ glial cells
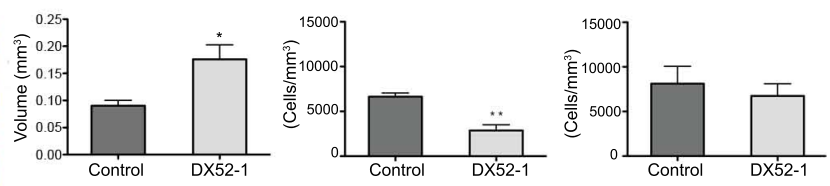

(F) There was no difference in the volume of the anterior RMS of vehicle and DX52-1 treated animals. (I) The volume of the posterior RMS was increased after infusion of DX52-1. (G, J) The number of $\mathrm{PHH} 3$ and PSA-NCAM double positive cells in the anterior $(\mathbf{G})$ and posterior $(\mathbf{J})$ RMS was decreased after 4 days of DX52-1 intracerebroventricular infusion. However, there was no difference in the number of $\mathrm{PHH} 3$ positive/PSA-NCAM negative cells in the anterior $\mathbf{( H )}$ or posterior RMS (K) $\left.{ }^{*} p<0.05,{ }^{*} p<0.01\right)$. Scale bar in $(\mathbf{A})=50 \mu \mathrm{m}$, scale bar in $\left(E^{\prime \prime}\right)=10 \mu \mathrm{m}$. 
Table 1 | Proteins with altered expression level after radixin inhibition in the SVZ as detected by isobaric labeling and mass spectrometry.

\begin{tabular}{|c|c|c|c|c|}
\hline Accession no. & Description & Foldchange & $p$-value & CV (\%) \\
\hline Q9WV97 & Mitochondrial import inner membrane translocase subunit Tim9 & 1.21 & 0.05 & 8.13 \\
\hline P61227 & Ras-related protein Rap-2b & 1.20 & 0.05 & 5.73 \\
\hline Q6AYH5 & Dynactin subunit 2 & 1.19 & 0.02 & 5.45 \\
\hline P31662 & Orphan sodium- and chloride-dependentneurotransmitter transporter NTT4 (SIc6a17) & 1.13 & 0.05 & 4.58 \\
\hline G3V7P1 & Syntaxin-12 & 1.13 & 0.03 & 1.65 \\
\hline Q63537 & Synapsin-2 & 1.12 & 0.02 & 3.91 \\
\hline Q6P9V9 & Tubulin alpha-1B chain & 1.12 & 0.02 & 3.60 \\
\hline Q6P7B0 & Tryptophanyl-tRNA synthetase, cytoplasmic & 1.12 & 0.01 & 1.65 \\
\hline P50408 & V-type proton ATPase subunit F & 1.11 & 0.00 & 1.91 \\
\hline Q9JK11 & Reticulon-4/Nogo A & 1.11 & 0.03 & 2.31 \\
\hline P13221 & Aspartate aminotransferase, cytoplasmic & 1.10 & 0.02 & 3.11 \\
\hline P21571 & ATP synthase-coupling factor 6 , mitochondrial & 1.10 & 0.02 & 2.76 \\
\hline P04797 & Glyceraldehyde-3-phosphate dehydrogenase (GAPDH) & 1.10 & 0.01 & 2.37 \\
\hline O35824 & DnaJ homolog subfamily A member 2 & 1.09 & 0.05 & 3.08 \\
\hline P04636 & Malatedehydrogenase, mitochondrial & 1.08 & 0.02 & 2.64 \\
\hline Q4KM73 & UMP-CMP kinase & 1.08 & 0.03 & 1.81 \\
\hline Q8CFN2 & Cell division control protein 42 (Cdc42) & 1.08 & 0.01 & 0.98 \\
\hline Q63569 & $26 S$ protease regulatory subunit $6 \mathrm{~A}$ & 1.04 & 0.02 & 0.90 \\
\hline P27139 & Carbonic anhydrase 2 & 0.97 & 0.00 & 0.59 \\
\hline Q62950 & Dihydropyrimidinase-related protein 1 & 0.95 & 0.04 & 1.85 \\
\hline Q99PD4 & Actin-related protein $2 / 3$ complex subunit $1 \mathrm{~A}$ & 0.94 & 0.01 & 2.03 \\
\hline Q568Z9 & Phytanoyl-CoA hydroxylase-interacting protein & 0.91 & 0.02 & 3.26 \\
\hline O70196 & Prolyl endopeptidase & 0.90 & 0.01 & 2.25 \\
\hline Q04400 & Adenylate cyclase type 5 & 0.89 & 0.02 & 3.34 \\
\hline Q9ESB5 & N-terminal EF-hand calcium-binding protein 1 (Necab1) & 0.87 & 0.03 & 3.62 \\
\hline Q642G4 & Peroxisomal membrane protein PEX14 & 0.86 & 0.02 & 4.39 \\
\hline Q9Z1E1 & Flotillin-1/Reggie 2 & 0.85 & 0.03 & 4.19 \\
\hline B0BN85 & Suppressor of G2 allele of SKP1 homolog & 0.85 & 0.01 & 3.49 \\
\hline P29066 & Beta-arrestin-1 & 0.84 & 0.01 & 3.56 \\
\hline P31424 & Metabotropic glutamate receptor 5 & 0.82 & 0.01 & 5.03 \\
\hline Q64537 & Calpain small subunit 1 & 0.80 & 0.04 & 9.91 \\
\hline Q9JJ54 & Heterogeneous nuclear ribonucleo protein D0 & 0.80 & 0.04 & 9.27 \\
\hline
\end{tabular}

Coefficient of variance, $C V ; n=3,(p<0.05)$.

RMS. The accumulation of neuroblasts in the posterior parts of the RMS suggests that fewer neuroblasts migrate through the RMS. This was corroborated by an increased volume in the posterior RMS. However, this accumulation was not sufficient to cause any significant decrease in the volume of the anterior RMS indicating that neuroblast migration in the SVZ and posterior RMS may be hampered although sufficient to proceed through the RMS. A longer infusion period than 4 days may be required to reveal an effect along the entire RMS. Phosphorylation of radixin enables its binding to the actin cytoskeleton under control conditions. After DX52-1 treatment in vivo, thelevel of phosphorylated radixin immunoreactivity was low in the RMS. Thus, the aberrant neuroblast migration could be a result of decreased phosphorylation of radixin.

Furthermore, radixin has been shown to concentrate in the cleavage furrow of dividing cells (Sato et al., 1991) and may have a role in proliferation. We demonstrate a selective decrease in neuroblast proliferation in the RMS after intracerebroventricular infusion of DX52-1. Proliferation of other cell types (PSA-NCAM negative) was not affected. These data are in accordance with a study that tested DX52-1as a chemotherapeutic agent after a screening for molecules affecting growth of melanoma cells, which also express radixin (Plowman et al., 1995).

We have determined the effects on neuroblast migration and proliferation in vivo after DX52-1 infusion. However, the 


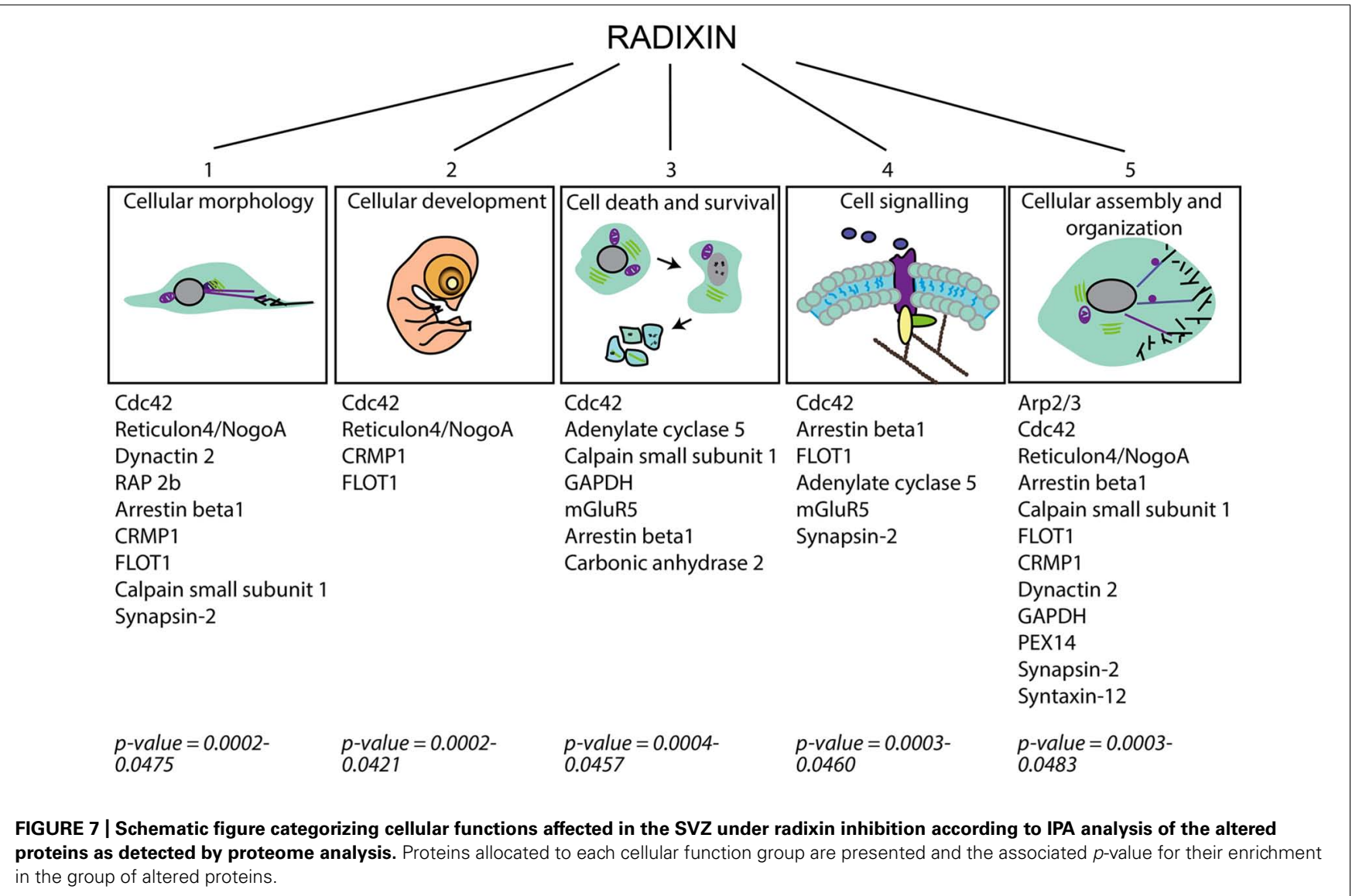

compound may have additional effects which are not related to neuroblast migration and proliferation. We could discern a moderate morphology change in the microglia population and an increase in the immunoreactivity of GFAP in the SVZ and corpus callosum (data not shown). Microdissection of DX521 treated brains indicated affected areas outside the SVZ/RMS and we observed vasculature changes in the thalamus, occasionally ventricle enlargement and softening of white matter tissue (data not shown). This may be explained by altered functions in non-neuroblast radixin expressing cells.

Considering recent evidence for regulation of cell functions by radixin other than migration (Loebrich et al., 2006; Tang et al., 2007; Valderrama et al., 2012), we quantified protein changes in the SVZ using a proteomic approach to identify biological functions affected by radixin inhibition in the neurogenic niche. It is important to consider that the proteomics analysis was based on a material of mixed cell types, and includes both intra- and extra-cellular proteins. This approach enables detection of general protein changes, including both primary and secondary events to the treatment. Our results show that the majority of the altered proteins have a role in cellular morphology and cellular assembly and organization which match our in vitro and in vivo results of radixin inhibition. Of the altered proteins $31 \%$ are abundantly expressed in the RMS according to the Allen brain atlas (http://mouse.brain-map.org), for example Reticulon 4/Nogo-A, Dynactin 2, and suppressor of G2 allele of SKP homolog. Cdc42 and Rac1 are members of the Rho family of small GTP-binding proteins, and radixinis known to interact with several Rho GTP-binding proteins and to regulate Racl activity (Takahashi et al., 1998; Hamada et al., 2001; Valderrama etal., 2012). Both Cdc42 and Racl are involved in neuronal embryonic migration but may have different roles (Konno et al., 2005). Cdc42 is for instance important for the guiding cues of the Slit-Robo pathway (Wong et al., 2001), suggesting a specific role in RMS migration. Calpain small subunit 1 is present in both calpain 1 and 2 and calpains regulate cell migration and adhesion (Huttenlocher et al., 1997; Dourdin et al., 2001). Recently, calpain 1 expression was shown to be high in neural stem cells and decreased during differentiation and calpain 1 inhibition increased neural stem cell differentiation (Santos et al., 2012). Contrary, calpain 2 was increased during neural stem cell differentiation (Santos et al., 2012). Furthermore, arrestins were initially acknowledged for their role in receptor internalization; however, recent evidence suggest a role for $\beta$ Arrestin-2 in promoting actin polymerization and migration of leukocytes (Zoudilova et al., 2010). The interaction of radixin with proteins identified in the proteomics analysis may be direct or indirect, or induced as a compensatory action to radixin inhibition. Future studies will have to address these issues. Our data suggest that radixin likely interacts with several different signaling or scaffolding proteins to mediate and/or regulate dynamic actin rearrangement. 
The effects of acute radixin inhibition in this study suggest that the functions of radixin in neuroblasts are not compensated by other actin binding proteins described in RMS neuroblasts, such as Girdin (Wang et al., 2011). However, the antibody against phosphorylated Ezrin/Radixin/Moesin does not discriminate between the three ERM proteins and thus, changes in phosphorylation levels could be due to any of the three proteins. We can exclude ezrin from being affected, since we do not see any effect on migration of glial cells, which express high levels of ezrin (Gronholm et al., 2005; Cleary et al., 2006; Persson et al., 2010) even at high doses of DX52-1. This confirms that DX52-1 seems not to generally block a common site on all three ERM proteins. In Persson et al. (2010), we show that close to all neuroblasts express radixin as the main ERM protein but also to a lower degree moesin, leaving the possibility that radixin and moesin could be affected by DX52-1. In the current study we observe that all radixin positive cells in the RMS loose

\section{REFERENCES}

Altman, J. (1969). Autoradiographic and histological studies of postnatal neurogenesis. IV. Cell proliferation and migration in the anterior forebrain, with special reference to persisting neurogenesis in the olfactory bulb. J. Comp. Neurol. 137, 433-457. doi: $10.1002 / \mathrm{cne} .901370404$

Anton, E. S., Ghashghaei, H. T., Weber, J. L., Mccann, C., Fischer, T. M., Cheung, I. D., et al. (2004). Receptor tyrosine kinase ErbB4 modulates neuroblast migration and placement in the adult forebrain. Nat. Neurosci. 7, 1319-1328. doi: 10.1038/nn1345

Arvidsson, A., Collin, T., Kirik, D., Kokaia, Z., and Lindvall, O. (2002). Neuronal replacement from endogenous precursors in the adult brain after stroke. Nat. Med. 8, 963-970. doi: 10.1038/nm747

Bono, P., Cordero, E., Johnson, K., Borowsky, M., Ramesh, V., Jacks, T., et al. (2005). Layilin, a cell surface hyaluronan receptor, interacts with merlin and radixin. Exp. Cell Res. 308, 177-187. doi: 10.1016/j.yexcr.2005.04.017

Bretscher, A., Edwards, K., and Fehon, R. G. (2002). ERM proteins and merlin: integrators at the cell cortex. Nat. Rev. Mol. Cell Biol. 3, 586-599. doi: 10.1038/nrm882

Castelo, L., and Jay, D. G. (1999). Radixin is involved in lamellipodial stability during nerve growth cone motility. Mol. Biol. Cell 10, 15111520. doi: $10.1091 / \mathrm{mbc} .10 .5 .1511$

Chazal, G., Durbec, P., Jankovski, A., Rougon, G., and Cremer, H. (2000). Consequences of neural cell adhesion molecule deficiency on cell migration in the rostral migratory stream of the mouse. J. Neurosci. 20, 1446-1457.

Cleary, M. A., Uboha, N., Picciotto, M. R., and Beech, R. D. (2006). Expression of ezrin in glial tubes in the adult subventricular zone and rostral migratory stream. Neuroscience 143, 851-861. doi: 10.1016/j.neuroscience.2006.08.028

Conover, J. C., Doetsch, F., GarciaVerdugo, J. M., Gale, N. W., Yancopoulos, G. D., and Alvarez-Buylla, A. (2000). Disruption of Eph/ephrin signaling affects migration and proliferation in the adult subventricular zone. Nat. Neurosci. 3, 1091-1097. doi: 10.1038/80606

Dourdin, N., Bhatt, A. K., Dutt, P., Greer, P. A., Arthur, J. S., Elce, J. S., et al. (2001). Reduced cell migration and disruption of the actin cytoskeleton in calpain-deficient embryonic fibroblasts. J. Biol. Chem. 276, 4838248388.

Ferri, A. L., Cavallaro, M., Braida, D., Di Cristofano, A., Canta, A., Vezzani, A., et al. (2004). Sox2 deficiency causes neurodegeneration and impaired neurogenesis in the adult mouse brain. Development 131, 3805-3819. doi: 10.1242/dev.01204

Ghashghaei, H. T., Weber, J., Pevny, L., Schmid, R., Schwab, M. H., Lloyd, K. C., et al. (2006). The role of neuregulin-ErbB4 interactions on the proliferation and organization of cells in the subventricular zone. Proc. Natl. Acad. Sci. U.S.A. 103, 19301935. doi: 10.1073/pnas.051041 0103

Gleeson, J. G., Lin, P. T., Flanagan, L. A., and Walsh, C. A. (1999). Doublecortin is a microtubuleassociated protein and is expressed widely by migrating neurons. Neuron 23, 257-271. doi: 10.1016/S08966273(00)80778-3

Gronholm, M., Teesalu, T., Tyynela, J., Piltti, K., Bohling, T., Wartiovaara, K., etal. (2005). Characterization of the NF2 protein merlin and the ERM protein ezrin in human, rat, and mouse central nervous system.

their pERM immunoreactivity upon DX52-1 incubation. We conclude from this that radixin is dephosphorylated and inactivated by DX52-1. However, we cannot exclude an additional contribution to the cellular effects from a possible inactivation of moesin.

\section{ACKNOWLEDGMENTS}

The authors declare no conflicts of interests. The authors thank Birgit Linder and Ann-Marie Alborn for excellent technical assistance, the Centre for Cellular Imaging and the Proteomics Core facility, both at the University of Gothenburg. This work was supported by grants from the Swedish Medical Research Council (www.vr.se), VästraGötaland regional funds for biomedical research (LUA-ALF), the Swedish Brain Foundation, StrokeRiksförbundet, Rune och Ulla Amlövsstiftelse, Stiftelsen Edit Jacobssonsdonationsfond and Stiftelsen Wilhelm och Martina LundgrensVetenskapsfond.

Mol. Cell. Neurosci. 28, 683-693. doi: 10.1016/j.mcn.2004.11.014

Haas, M. A., Vickers, J. C., and Dickson, T. C. (2007). Rho kinase activates ezrin-radixin-moesin (ERM) proteins and mediates their function in cortical neuron growth, morphology and motility in vitro. J. Neurosci. Res. 85, 34-46. doi: 10.1002/jnr.21102

Hamada, K., Seto, A., Shimizu, T., Matsui, T., Takai, Y., Tsukita, S. et al. (2001). Crystallization and preliminary crystallographic studies of RhoGDI in complex with the radixin FERM domain. Acta Crystallogr. D Biol. Crystallogr. 57, 889-890. doi: 10.1107/S090744490100556X

Huttenlocher, A., Palecek, S. P., Lu, Q., Zhang, W., Mellgren, R. L., Lauffenburger, D. A., et al. (1997). Regulation of cell migration by the calcium-dependent protease calpain. J. Biol. Chem. 272, 32719-32722. doi: 10.1074/jbc.272.52.32719

Ivetic, A., Deka, J., Ridley, A., and Ager, A. (2002). The cytoplasmic tail of L-selectin interacts with members of the ezrin-radixin-moesin (ERM) family of proteins: cell activationdependent binding of moesin but not ezrin. J. Biol. Chem. 277, 2321-2329. doi: 10.1074/jbc.M109460200

Jin, K., Wang, X., Xie, L., Mao, X. O., and Greenberg, D. A. (2010). Transgenic ablation of doublecortinexpressing cells suppresses adult neurogenesis and worsens stroke outcome in mice. Proc. Natl. Acad. Sci. U.S.A. 107, 7993-7998. doi: 10.1073/pnas.1000154107

Kahsai, A. W., Zhu, S., Wardrop, D. J., Lane, W. S., and Fenteany, G. (2006). Quinocarmycin analog DX52-1 inhibits cell migration and targets radixin, disrupting interactions of radixin with actin and CD44. Chem. Biol. 13, 973-983. doi: 10.1016/j.chembiol.2006.07.011
Kim, Y., Comte, I., Szabo, G., Hockberger, P., and Szele, F. G. (2009). Adult mouse subventricular zone stem and progenitor cells are sessile and epidermal growth factor receptor negatively regulates neuroblast migration. PLoS ONE 4:e8122. doi: 10.1371/journal.pone.0008122

Koizumi, H., Higginbotham, H., Poon, T., Tanaka, T., Brinkman, B. C., and Gleeson, J. G. (2006). Doublecortin maintains bipolar shape and nuclear translocation during migration in the adult forebrain. Nat. Neurosci. 9, 779-786. doi: 10.1038/nn1704

Konno, D., Yoshimura, S., Hori, K., Maruoka, H., and Sobue, K. (2005). Involvement of the phosphatidylinositol 3-kinase/racl and cdc42 pathways in radial migration of cortical neurons. J. Biol. Chem. 280, 5082-5088. doi: 10.1074/jbc.M40825 1200

Li, L., Harms, K. M., Ventura, P. B., Lagace, D. C., Eisch, A. J., and Cunningham, L. A. (2010). Focal cerebral ischemia induces a multilineage cytogenic response from adult subventricular zone that is predominantly gliogenic. Glia 58, 1610-1619.

Lindberg, O. R., Brederlau, A., Jansson, A., Nannmark, U., CooperKuhn, C., and Kuhn, H. G. (2012). Characterization of epidermal growth factor-induced dysplasia in the adult rat subventricular zone. Stem Cells Dev. 21, 1356-1366. doi: 10.1089/scd.2011.0275

Loebrich, S., Bahring, R., Katsuno, T., Tsukita, S., and Kneussel, M. (2006). Activated radixin is essential for GABAA receptor alpha5 subunit anchoring at the actin cytoskeleton. EMBO J. 25, 987-999. doi: 10.1038/sj.emboj.7600995

Lois, C., and Alvarez-Buylla, A. (1994). Long-distance neuronal migration in the adult mammalian brain. Science 
264, 1145-1148. doi: 10.1126/science. 8178174

Lois, C., Garcia-Verdugo, J. M., and Alvarez-Buylla, A. (1996). Chain migration of neuronal precursors. Science 271, 978-981. doi: 10.1126/science.271.5251.978

Luskin, M. B. (1993). Restricted proliferation and migration of postnatally generated neurons derived from the forebrain subventricular zone. $\mathrm{Neu}$ ron 11, 173-189. doi: 10.1016/08966273(93)90281-U

Mirzadeh, Z., Doetsch, F., Sawamoto, K., Wichterle, H., and Alvarez-Buylla, A. (2010). The subventricular zone en-face: wholemount staining and ependymal flow. J. Vis. Exp. 39, 1938.

Ono, K., Tomasiewicz, H., Magnuson, T., and Rutishauser, U. (1994). $\mathrm{N}-\mathrm{CAM}$ mutation inhibits tangential neuronal migration and is phenocopied by enzymatic removal of polysialic acid. Neuron 13, 595-609. doi: 10.1016/0896-6273(94)90028-0

Osman, A. M., Porritt, M. J., Nilsson, M., and Kuhn, H. G. (2011). Long-term stimulation of neural progenitor cell migration after cortical ischemia in mice. Stroke 42, 3559-3565. doi: 10.1161/STROKEAHA.111.627802

Paglini, G., Kunda, P., Quiroga, S., Kosik, K., and Caceres, A. (1998). Suppression of radixin and moesin alters growth cone morphology, motility, and process formation in primary cultured neurons. J. Cell Biol. 143, 443-455. doi: 10.1083/jcb.143.2.443

Parisiadou, L., Xie, C., Cho, H. J., Lin, X., Gu, X. L., Long, C. X., etal. (2009). Phosphorylation of ezrin/radixin/moesin proteins by LRRK2 promotes the rearrangement of actin cytoskeleton in neuronal morphogenesis. J. Neurosci. 29, 13971-13980. doi: 10.1523/JNEUROSCI.3799-09.2009

Peretto, P., Merighi, A., Fasolo, A., and Bonfanti, L. (1997). Glial tubes in the rostral migratory stream of the adult rat. Brain Res. Bull. 42, 9-21. doi: 10.1016/S0361-9230(96)00116-5

Persson, A., Lindwall, C., Curtis, M. A., and Kuhn, H. G. (2010). Expression of ezrin radixin moesin proteins in the adult subventricular zone and the rostral migratory stream. Neuroscience 167, 312-322. doi: 10.1016/j.neuroscience.2010.01.035

Plowman, J., Dykes, D. J., Narayanan, V. L., Abbott, B. J., Saito, H., Hirata, T., etal. (1995). Efficacy of the quinocarmycins KW2152 and DX52-1 against human melanoma lines growing in culture kand in mice. Cancer Res. 55, 862-867.

Rolando, C., Parolisi, R., Boda, E., Schwab, M. E., Rossi, F., and Buffo, A. (2012). Distinct roles of Nogo-a and Nogo receptor 1 in the homeostatic regulation of adult neural stem cell function and neuroblast migration. J. Neurosci. 32, 17788-17799. doi: 10.1523/JNEUROSCI.3142-12. 2012

Santos, D. M., Xavier, J. M., Morgado, A. L., Sola, S., and Rodrigues, C. M. (2012). Distinct regulatory functions of calpain 1 and 2 during neural stem cell self-renewal and differentiation. PLOS ONE 7:e33468. doi: 10.1371/journal.pone. 0033468

Sato, N., Funayama, N., Nagafuchi, A., Yonemura, S., and Tsukita, S. (1992). A gene family consisting of ezrin, radixin and moesin. Its specific localization at actin filament/plasma membrane association sites. J. Cell Sci. 103(Pt 1), 131-143.

Sato, N., Yonemura, S., Obinata, T. Tsukita, S., and Tsukita, S. (1991). Radixin, a barbed end-capping actinmodulating protein, is concentrated at the cleavage furrow during cytokinesis. J. Cell Biol. 113, 321-330. doi: 10.1083/jcb.113.2.321

Serrador, J. M., Alonso-Lebrero, J. L., Del Pozo, M. A., Furthmayr, H., Schwartz-Albiez, R., Calvo, J., et al. (1997). Moesin interacts with the cytoplasmic region of intercellular adhesion molecule-3 and is redistributed to the uropod of $\mathrm{T}$ lymphocytes during cell polarization. J. Cell Biol. 138, 1409-1423. doi: 10.1083/jcb.138.6.1409

Takahashi, K., Sasaki, T., Mammoto, A., Hotta, I., Takaishi, K., Imamura, H., etal. (1998). Interaction of radixin with Rho small $G$ protein GDP/GTP exchange protein Dbl. Oncogene 16, 3279-3284. doi: 10.1038/sj.onc. 1201874

Takai, Y., Kitano, K., Terawaki, S., Maesaki, R., and Hakoshima, T. (2007). Crystallographic characterization of the radixin FERM domain bound to the cytoplasmic tails of adhesion molecules CD43 and PSGL1. Acta Crystallogr. Sect. F Struct. Biol. Cryst. Commun. 63, 49-51. doi: 10.1107/S1744309106054145

Tang, P., Cao, C., Xu, M., and Zhang, L. (2007). Cytoskeletal protein radixin activates integrin alpha(M)beta(2) by binding to its cytoplasmic tail. FEBS Lett. 581, 1103-1108. doi: 10.1016/j.febslet.2007.02.013

Terawaki, S., Kitano, K., Aoyama, M., and Hakoshima, T. (2008). Crystallographic characterization of the radixin FERM domain bound to the cytoplasmic tail of membrane-type 1 matrix metalloproteinase (MT1-MMP). Acto Crystallogr. Sect. F Struct. Biol. Cryst. Commun. 64, 911-913. doi: 10.1107/S1744309108026869

Tsukita, S., Yonemura, S., and Tsukita, S. (1997). ERM proteins: head-totail regulation of actin-plasma membrane interaction. Trends Biochem. Sci. 22, 53-58. doi: 10.1016/S09680004(96)10071-2

Valderrama, F., Thevapala, S., and Ridley, A. J. (2012). Radixin regulates cell migration and cell-cell adhesion through Racl. I. Cell Sci. 125, 33103319. doi: 10.1242/jcs.094383

Wang, Y., Kaneko, N., Asai, N. Enomoto, A., Isotani-Sakakibara, M., Kato, T., et al. (2011). Girdin is an intrinsic regulator of neuroblast chain migration in the rostral migratory stream of the postnatal brain. J. Neurosci. 31, 8109-8122. doi: 10.1523/JNEUROSCI.1130-11.2011

Wong, K., Ren, X. R., Huang, Y. Z., Xie, Y., Liu, G., Saito, H., et al. (2001). Signal transduction in neuronal migration: roles of GTPase activating proteins and the small GTPase Cdc42 in the Slit-Robo pathway. Cell 107, 209-221. doi: 10.1016/S00928674(01)00530-X

Zoudilova, M., Min, J., Richards, H. L., Carter, D., Huang, T., and Defea, K. A. (2010). beta-Arrestins scaffold cofilin with chronophin to direct localized actin filament severing and membrane protrusions downstream of protease-activated receptor-2. J. Biol. Chem. 285, 14318-14329. doi: 10.1074/jbc.M109.055806

Conflict of Interest Statement: The authors declare that the research was conducted in the absence of any commercial or financial relationships that could be construed as a potential conflict of interest.

Received: 14 May 2013; accepted: 03 September 2013; published online: 24 September 2013.

Citation: Persson $\AA$, Lindberg $O R$ and Kuhn HG (2013) Radixin inhibition decreases adult neural progenitor cell migration and proliferation in vitro and in vivo. Front. Cell. Neurosci. 7:161. doi: 10.3389/fncel.2013.00161

This article was submitted to the journal Frontiers in Cellular Neuroscience. Copyright (c) 2013 Persson, Lindberg and Kuhn. This is an open-access article distributed under the terms of the Creative Commons Attribution License (CC BY). The use, distribution or reproduction in other forums is permitted, provided the original author(s) or licensor are credited and that the original publication in this journal is cited, in accordance with accepted academic practice. No use, distribution or reproduction is permitted which does not comply with these terms. 